\title{
Higher Education and Social Media: An Empirical Evidence from Jordan and Malaysia
}

\author{
Amjad Omar Safori' ${ }^{1}$, Nik Adzrieman B. Abd Rahman² \\ ${ }^{1}$ School of Journalism \& Mass Communication, Zarqa University, Zarqa, Jordan \\ ${ }^{2}$ School of Multimedia Technology \& Communication, University Utara Malaysia, Sintok, Malaysia \\ Email: asafori@zu.edu.jo, adzrieman@uum.edu.my
}

How to cite this paper: Safori, A. O., \& Rahman, N. A. B. A. (2019). Higher Education and Social Media: An Empirical Evidence from Jordan and Malaysia. Advances in Journalism and Communication, 7, 118-128. https://doi.org/10.4236/ajc.2019.74008

Received: October 15, 2019

Accepted: November 22, 2019

Published: December 11, 2019

Copyright $\odot 2019$ by author(s) and Scientific Research Publishing Inc. This work is licensed under the Creative Commons Attribution International License (CC BY 4.0).

http://creativecommons.org/licenses/by/4.0/

\begin{abstract}
In the last decade, social media seeks the attention of many researchers. As prior studies argued, that social media has dynamic capabilities to interact and accessibility among students. Social media is one of those factors, who has the ability to play an essential role in a dynamic learning environment. The uniqueness of social media opens new horizons for students to enhance their experiences in the field of higher education. It has been observed that the adaptation of social media is a phenomenon among students of higher education. In this study, the researcher examines the relationship between lecturer and students through social media. This study took a convenience sample data from undergraduate students of Malaysia and Jordan. The main objective of this study is to explore the motivation of students to words social media for educational purposes. Secondly, this study also investigates the perception of social media as a communication tool for lecturers and students. Moreover, the researcher highlighted the attitude differences among Malaysian and Jordanian students. The study found that respondents are the frequent user of SM, and the most popular media is Facebook among them. Results show that students are reluctant to use SM for educational communication. However, if lecturers took this initiative and engaged students on SM for educational purposes, then students' attitude was more optimistic. Additionally, students consider SM as a powerful tool that has the potential to strengthen the level of communication between students and the lecturer.
\end{abstract}

\section{Keywords}

Social Networking, Learning Process, Higher Education, Student-Teacher Interaction, Social Media

\section{Introduction}

In the era of technology, social networks (SN) and social media (SM) trans- 
formed the traditional ways of communicating and interacting with our friends and peers. These advanced tools also affect the consumption behavior of media content. SM gives us the freedom to create our digital content. The evolutional process of SM is quite impressive; only a decade ago, it is just providing a platform for informal chit chat only. It has no commercial value outside the IT industry. However, SM dramatically grape the attention of masses, and this creates an opportunity for commercial exploitation. Moreover, the marketing companies are shifting their budgets from traditional media (electronic and print media) toward more interactive and dynamic SM (Jain \& Yadav, 2017).

This era of digitalization is not only affecting the traditional way of communications but also changing the conventional methods of academia. Its high rate of adoption and popularity among students makes it more relevant for education. Its dynamic interaction has enormous potential to use as an education tool (e.g., Sheldon, 2015; Ellefsen, 2016; Dabbagh \& Kitsantas, 2012; Draskovic et al., 2013). Moreover, the educators have enough potential to grape the opportunities that SM offers through its dynamic tools and capability to engaged students (Moran et al., 2011). However, this medium of communication has some challenges and reservations among the lecturers. These challenges are creating hurdles for the full adoption of SM as an educational tool. The educators have different opinions regarding the role of SM in higher education because of its informal perception (Madge et al., 2009).

This study will elaborate on the concept of SM to develop an understanding of its significant contribution to the learning process. The prior studies argued that SM is a community of Internet platforms that is developed on the technological concept of Web 2.0 that facilitates the formation and exchange of commonly created content (Safori, 2018; Kaplan \& Haenlein, 2010). Safori (2018) stated that SM gathers several means of communication, including media sharing tools, networking platforms, blogs, wikis, and virtual worlds. These technologically advanced tools are served in different social purposes, such as social interaction facilitation, teamwork possibilities, and generate a discussion across the users. Furthermore, the researcher argued that SM has multiple tools to facilitate educational implementation. It can be promoted as a media to broadcast lectures and documentaries.

Moreover, it has observed that the contribution of the learning process varies among the different SM platforms. For example, blogs are more focused on authorship as compared to wikis being a tool that made for teamwork and mutual contributions (Bryer \& Zavatarro, 2011). However, the SM should be highly focused on contextualization and integration of knowledge while it is working in the educational environment.

However, researchers highlighted the current vulnerability of SM with the help of the learner-centered model and constructivist learning theory. A process in which a person produces the knowledge and on the other hand, a person merely gaining it through the traditional model of learning (Duffy \& Cunningham, 1996). This method explains learning as a social process. 
According to Siemens (2005), the traditional learning theory has extended its vision in the context of SM. As the author argued that it is not that simple to initiate a learning process in a person. However, many other essential connections must be available to start the learning process. Therefore, Siemens identified this complex mechanism and proposed a new learning theory; called "connectivism". Following are principles on which this theory relies (2005, p7):

- Capacity and hunger for more knowledge are more important than what is currently known;

- The core skill is the ability to explore connections among concepts, ideas, and fields;

- Learning may reside in non-human appliances;

- To facilitate sustainable learning, it is necessary to develop secure connections;

- Diversity of thoughts is the key to learning and knowledge;

- Learning thorough decision making is a continuous process. The decision of what to learn and analyzing the upcoming information with the lens of shifting reality is critical. Furthermore, if there is a satisfactory answer now, but it might be wrong in the future due to alternative information affecting the decision;

- Learning is a process of connecting specialized nodes or information sources;

- Currency (accurate, up-to-date knowledge) is the intent of all connectivism learning activities.

Regarding discussion, as mentioned above, SM is a platform that has such an ability to interact and collaborate with the learning process. Its dynamic capability will contribute to knowledge creation through contextualization and a meaningful learning process. The outcomes of learning can be more effectively monitor through SM. Further, moreover, SM provides a familiar environment for students, and it will help them to enhance their academic knowledge as well as intellectual development (King, 2011). As collaboration and participation are the crucial aspects of learning that can be provided through SM communication.

Statista (2016) argued that only Facebook has more than 1.5 billion active users only all over the world. And if it includes other platforms such as Twitter, Instagram, etc. with hundreds of millions of users. Moreover, SM recognized as a popular communication platform in the developed world. SM is not only a communication tool, but now it will become an essential part of our life. Moreover, SM gained incredible acceptance as a necessary and cheap tool for communication.

In the higher education system, it also used as an educational tool because of its higher rate of adoption among the students and its capability to improve student's interest and participation in educational projects. It could be claimed that SM platforms bring a radical change in the field of ethic, art, culture, economics, science, and education. Moreover, the use of SM platforms is highly appreciated and showing a growing trend in the field of higher education (Kassens-Noor, 2012; Taylor et al., 2012; Ellefsen, 2016). 
Although SM presented more effective ways of learning for scholars. However, it has been observed that lecturers are not share the same level of enthusiasm because it looks less formal communication platform (Draskovic et al., 2013). Additionally, the utilization of SM as a mean of communication tool for teaching requires additional skills, like typing and enough knowledge of computer use. Most of the students have sufficient computer skills to manage digital media (Bodle, 2011). However, most of the lecturers have a lack of understanding regarding SM and advanced application of communications. In faculty, there is a lot of room for improvement and awareness required for the use of digital media (Krumsvik, 2014; Krumsvik, 2008; Tømte et al., 2015).

E-learning is formally known as the course management system (CMS) is one of the comprehensive systems to engage students effectively. These platforms help to overcome the problem of student's collaboration, engagement, and interaction. The student learning outcomes are strongly linked with the student's participation in the contemporary classroom. Although CMS has excellent features of controlled collaborations, that attracts the lectures. But the track record of this system shows that it's difficult to achieve the required results from this system (Bryer \& Chen, 2012). However, there is no comparison between CMS and SM as a learning tool. Since it is challenging to cultivate its benefits because it required a creative environment through which students can contribute in this system (McLoughlin \& Lee, 2008).

Furthermore, the discussion, as mentioned earlier, explains the communication between lecturers and students. In this particular paper, the researcher discoursed the teacher revelation through Facebook (i.e. the quantity of information that a lecturer reveals to students) and its impression on the student learning, classroom environment, and motivation if student and teacher originate a positive correlation between them. Then it interprets that higher revelation improves the stated factors. This kind of response is very crucial for the lecturer because it provides a valuable understanding of the lecturer that whether students are taking activity as favorable or not. Moreover, such feedback empowered the lecturer to create a more effective digital image for his students. To develop a reliable and effective digital model for students is far easy as compared to create such an image in face to face communication. The presence of instructors on Facebook will enhance the motivation level of students and also inspired them to develop themselves as a brand.

SM is also crucial through simulated communication or what can be called computer-mediated communication (CMC). Concerning this specific channel, Mazer et al. (2007) claim that "the use of CMC in the instructional context, could ultimately have a positive effect on the student-teacher relationship, which can lead to more positive student outcomes". Prior studies suggest (Dabbagh \& Kitsantas, 2011; Ellefsen, 2016; Sheldon, 2015; Pestek et al., 2012) that SM has enough potential to use an educational tool. It could improve student class participation and motivation levels. Although, it depends on both teachers and students how they used and implemented of SM in the classroom. 


\section{Methodology}

This study provides a comprehensive analysis between the student and lecturer through SM. Furthermore, this study also explores the possible differences in SM use among the Jordanian and Malaysian students at the higher education level. In light of the recommendations of the previous literature, there is substantial potential in SM that it can be used as an educational tool for higher education. Although, it is also observed that there are some barriers in adaption of SM for both students and lecturers. However, this study aims to further investigate the student motivation for the use of SM in the context of student and instructor interaction. In the previous studies, the role of SM is discussed with the perspective of both student and lecturer, but in this study, the author only focuses on the student motivation for SM use.

Previous studies provide a summary of the views on social media of both lecturers and students, but this research is focused on the student side. The countries and respondents are carefully selected according to the growth of economies. In September 2018, this research was simultaneously conducted in Jordan and Malaysia. The survey was done with the help of the convenience sample technique in both countries. This study was conducted online through structural questionnaires, and participation was voluntary. The total sample was taken for this research is 330 out of which 168 students were from Jordan, and 172 students were from Malaysia. The age of respondents is between 18 and 32, out of which $45.6 \%$ are identified as female, and $54.4 \%$ are male.

With the help of extensive literature review and senior scholar, the following hypotheses were developed:

- H1: Students used SM on a daily basis, both Jordanian and Malaysian;

- H2: Students are open to using SM for educational purposes;

- H3: Students tend to use SM to connect with their lecturers;

- H4: Jordanian and Malaysian students vary in attitudes towards teacher-student interactions via SM.

\section{Results and Discussion}

Through a structural questionnaire, participants expressed their experiences regarding access, use, and platform of social media. Most respondents used different SM platforms. The majority (93.7\%) used SM daily. There is no significant difference between Malaysian and Jordanian students regarding the use of advanced gadgets and SM availability options. It has been observed that most of the students in both counties have easy access to SM through their devices (Figure 1).

Moreover, the respondent from both countries Malaysia and Jordan disclosed that there is no significant change in their motivation to use SM. Among the different choices, the most motivated reason to use SM is to stay connected with friends (71.5\%), and the second one is getting updated with current events (70.3\%). 


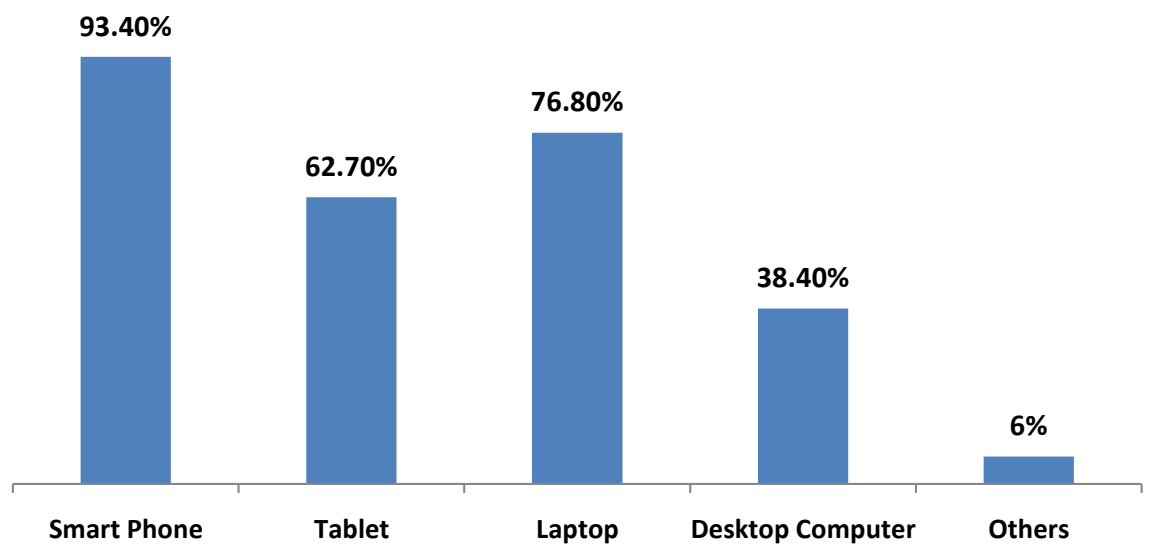

Figure 1. SM access (multiple answers were possible).

Among the different platforms of SM, the respondent's most popular SM platform is Facebook (93.4\%), YouTube (85.6\%), Instagram and Skype by (63.8\%).

This study found that only $36.9 \%$ of students communicated through SM with their teachers. There is a significant difference between Malaysian and Jordanian students in the context of commutation with their lecturers. Students in Malaysia are less vocal (17\%) relative to students in Jordan (58\%). Surprisingly, in the future they are less willing to change that behavior (17.4\% vs. $56.4 \%) .34 .2$ percent of respondents, however, are eager in the future to connect with their lecturers via SM.

In response to the use of SM for educational purposes (53.7\%), respondents used to do communication with their respected lectures regarding course assignments (46.3). However, the respondent also claimed that after graduation, they used to stay in touch with the faculty members through SM (39\%). The student's response is heterogeneous (Figure 2), regarding their attitude towards voluntary interaction of SM, for the sake of higher education. Furthermore, most of the respondents remained neutral while they expressed their attitude. Results show's that students have a lack of motivation to use SM for education purposes.

Figure 3 described that if the course lecturer took the initiative to use SM for education purposes, then students show a positive attitude towards SM. Results also indicate that only less than $10 \%$ of students are not organized to participate. Overall, the study found that there are no significant differences between students of Malaysia and Jordan.

Overall, this study shows that most of the participants had a favorable opinion regarding the use of SM for higher education (Figure 4). Most of the students strongly agreed (63.3\%) that SM has enough potential to use an important tool for education. Moreover, a significant majority of students (58.8\%) emphasized that $\mathrm{SM}$, as a device, can improve communication among students and lectures. Additionally, $74 \%$ of respondents believed that SM could also help to enhance communication between enrolled students of the same class. However, the study found that students are quite an optimist regarding the use of SM form education. A significant number of respondents claimed that they would like to exploit 


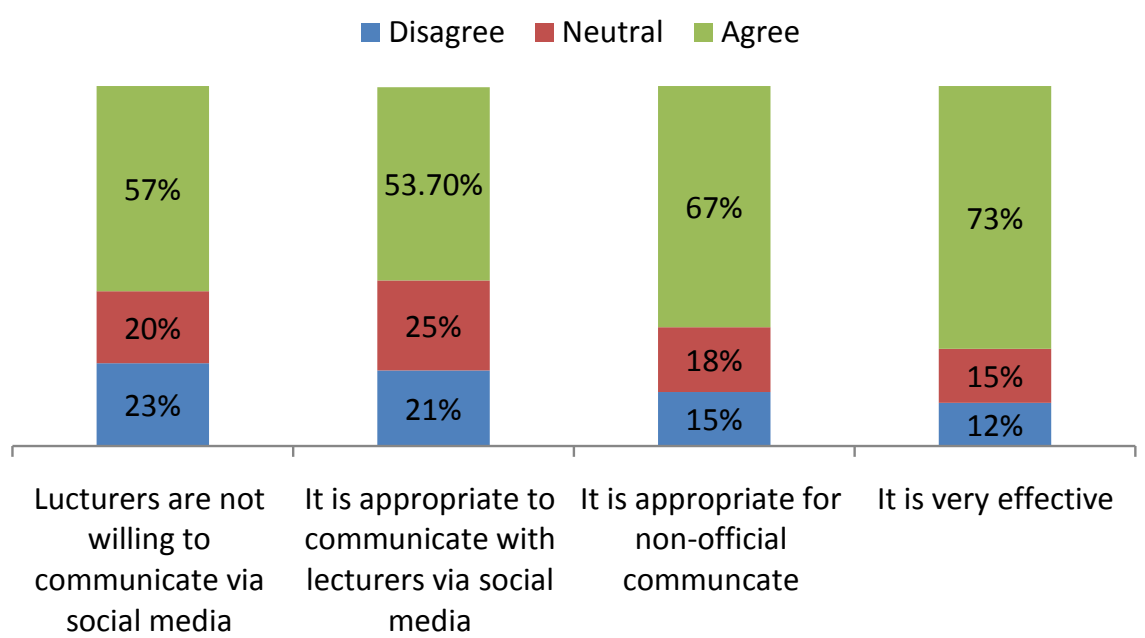

Figure 2. Respondent opinion (communication between student and lecturers via SM).

- I would not participate $\quad$ I might participate I would likely participate

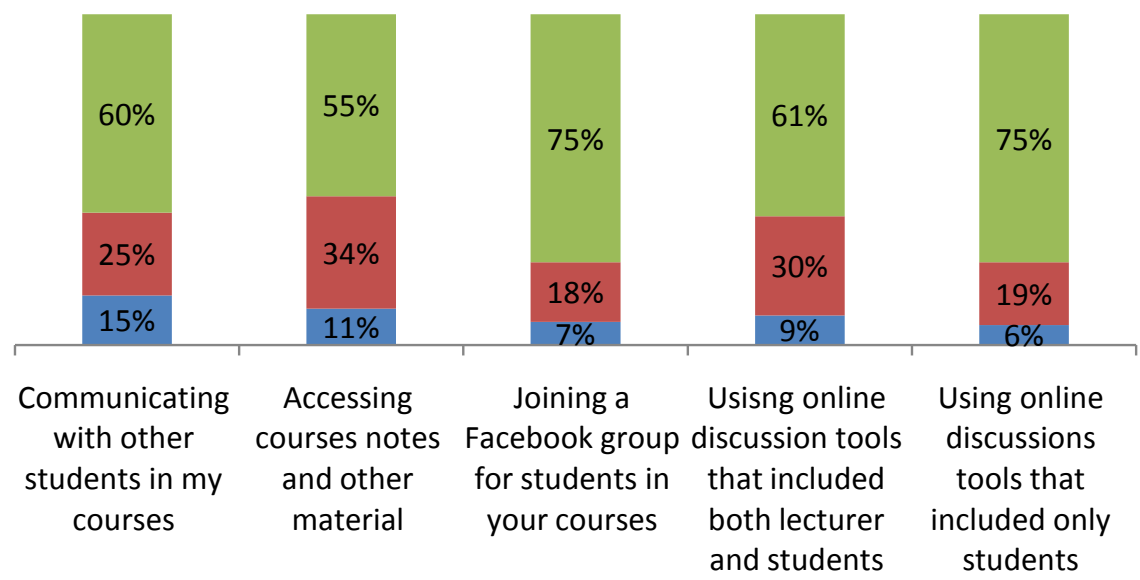

Figure 3. Students participation (in case lecturers recommend SM for communication).

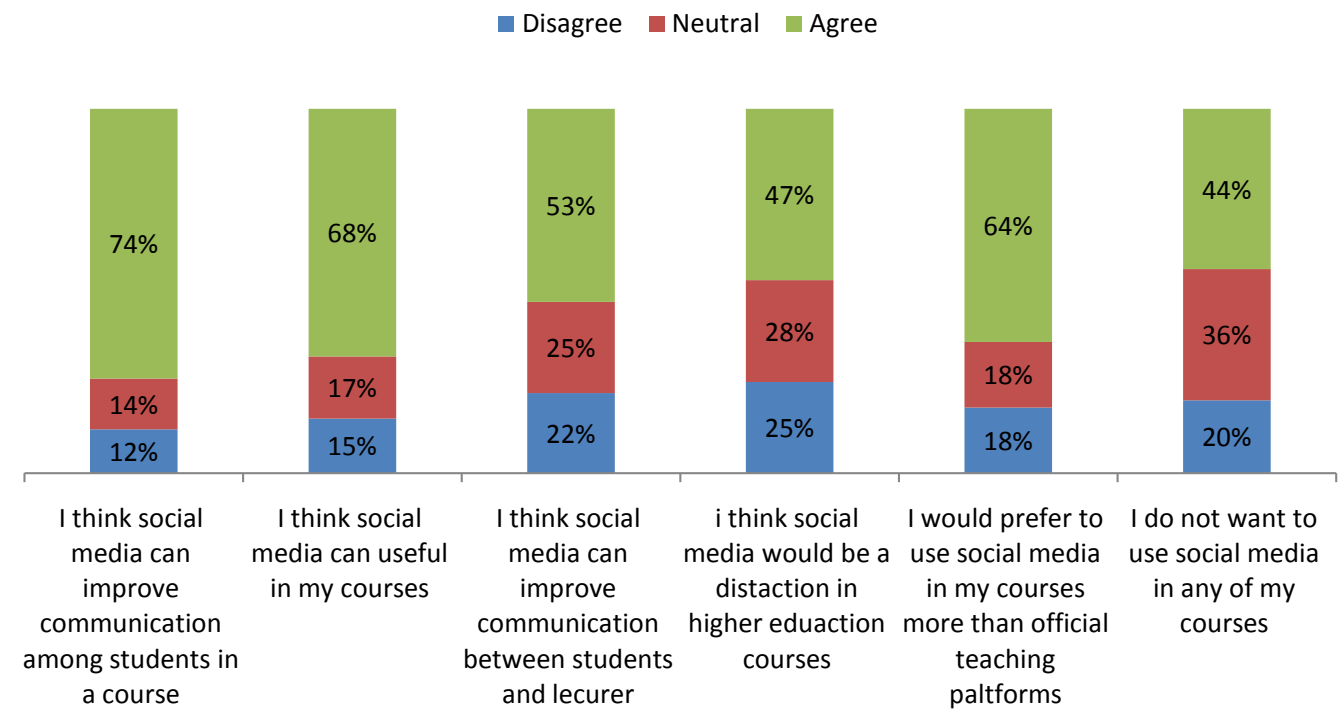

Figure 4. Student opinion (SM as an educational tool). 
all the existing online platforms provided by the university. Meanwhile, again, the study did not found any significant difference between Malaysian and Jordanian students.

Based on previous results, this study found that respondents are the frequent user of SM, and the most popular media is Facebook among them. However, the students from Malaysia and Jourdan are the daily user of SM; this finding supports H1. Students used laptops and smartphones to access SM that is consistent with the global tendency. The advance level use of different gadgets discloses the logic behind the shift of marketing budgets from traditional media to digital media (Statista, 2016).

Results show that students are reluctant to use SM for educational communication. Most of the students gave a neutral opinion on the use of SM for communication with lecturers. However, if lecturers took this initiative and engaged students on SM for educational purposes, then students' attitude was more optimistic. $\mathrm{H} 2$ is accepted because lecturers are the primary motivators behind the involvement of students on SM for educational purposes.

Most of the students have a positive attitude towards the use of SM for educational purposes; thus, $\mathrm{H} 3$ can be accepted. Additionally, students consider SM as a powerful tool that has the potential to strengthen the level of communication between students and the lecturer. However, there are still many students who preferred CMS for communication. But there is enough room to placed SM as a second option for more effective communication.

Moreover, the study found that as compared to Jordanian students, Malaysian students did less communication with their lectures through SM and unwilling to improve it in the future. This stubbing attitude of the students could be explained through cultural norms. As the environment of Malaysian institutes are more formal and authoritarian. The factor of the environment should be investigated in future studies. However, this study did not find any significant differences in the perspective of SM among the students of Malaysian and Jourdan; consequently, $\mathrm{H} 4$ is not accepted.

\section{Conclusion}

The study found that the use of SM is quite similar in both counties Malaysia and Jordan; however, it has been observed that a small group of students used SM only for communication. Moreover, the study highlighted that many students are not currently engaged with lectures through SM, but they showed their commitment to do it in the future. These strong indicators translate the phenomena of SM among students that they are forecasting and admitting the critical role of SM in the field of education. This kind of engagement will be increased the learning experience of both students and lecturers.

This study recommends that students are the regular users of social media, and they have an optimistic attitude to integrate SM in education. But they are reluctant to use it; however, lecturers are the primary source of motivation for 
students. Through the lecturer's recommendation, students should be participated and emerged SM as a dynamic tool of communication. Currently, students choose SMS for educational communication; however, they are willing to continue it in the future as well. Moreover, this study exposes that the attitude toward the use of SM has no significant differences between the students of Malaysia and Jordan.

Due to limited time and resources, this study has some limitations. The sample size is one of the restrictions, along with the sampling technique. This study used a relatively small sample size as this sample size does not truly represent the entire population or society. So, the results of this study do not generalize to the whole community. However, the findings of this study should be measured as signals. Moreover, other variables can also be included to interpret the entire phenomenon more clearly. So the objectivity of the research and intensity of the results should be reported on a larger scale.

The role of SM in education is quite interesting because literature continuously highlighted its benefits for students as well as teachers. Moreover, this study found that students and lectures both have some constraints regarding the use of social media. However, educators or lectures have enough ethical power, that if they took initiative and use it for educational purposes. Then, the students should automatically adopt the SM for educational communication. This study recommends that future studies should be conducted on the motivational behavior of the students towards the use of SM for educational communication. Nonetheless, the acceptance rate of lecturers and their propensity to use SM as an educational tool often require additional researchers' attention.

\section{Conflicts of Interest}

The authors declare no conflicts of interest regarding the publication of this paper.

\section{References}

Bodle, R. (2011). Social Learning with Social Media: Expanding and Extending the Communication Studies Classroom. In Teaching Arts and Science with the New Social Media (pp. 107-126). Bingley: Emerald Group Publishing Limited. https://doi.org/10.1108/S2044-9968(2011)0000003009

Bryer, T. A., \& Zavattaro, S. M. (2011). Social Media and Public Administration: Theoretical Dimensions and Introduction to the Symposium. Administrative Theory \& Praxis, 33, 325-340. https://doi.org/10.2753/ATP1084-1806330301

Chen, B., \& Bryer, T. (2012). Investigating Instructional Strategies for Using Social Media in Formal and Informal Learning. The International Review of Research in Open and Distributed Learning, 13, 87-104. https://doi.org/10.19173/irrodl.v13i1.1027

Dabbagh, N., \& Kitsantas, A. (2012). Personal Learning Environments, Social Media, and Self-Regulated Learning: A Natural Formula for Connecting Formal and Informal Learning. The Internet and Higher Education, 15, 3-8.

https://doi.org/10.1016/j.iheduc.2011.06.002

Draskovic, N., Caic, M., \& Kustrak, A. (2013). Croatian Perspective(s) on the Lectur- 
er-Student Interaction through Social Media. International Journal of Management Cases, 15, 331.

Duffy, T. M., \& Cunningham, D. J. (1996). Constructivism: Implications for the Design and Delivery of Instruction. In D. H. Jonassen (Ed.), Handbook of Research for Educational Communications and Technology (pp. 170-198). New York: Macmillan Library Reference.

Ellefsen, L. (2016). An Investigation into Perceptions of Facebook-Use in Higher Education. International Journal of Higher Education, 5, 160-172. https://doi.org/10.5430/ijhe.v5n1p160

Jain, E., \& Yadav, A. (2017). Marketing and Technology: Role of Technology in Modern Marketing. IOSR Journal of Business and Management, 19, 49-53. https://doi.org/10.9790/487X-1905064953

Kaplan, A. M., \& Haenlein, M. (2010). Users of the World, Unite! The Challenges and Opportunities of Social Media. Business Horizons, 53, 59-68. https://doi.org/10.1016/j.bushor.2009.09.003

Kassens-Noor, E. (2012). Twitter as a Teaching Practice to Enhance Active and Informal Learning in Higher Education: The Case of Sustainable Tweets. Active Learning in Higher Education, 13, 9-21. https://doi.org/10.1177/1469787411429190

King, R. (2011). Metacognition: Information Literacy and Web 2.0 as an Instructional Tool. Currents in Teaching and Learning, 2, 22-32.

Krumsvik, R. J. (2008). Situated Learning and Teachers' Digital Competence. Education and Information Technologies, 13, 279-290. https://doi.org/10.1007/s10639-008-9069-5

Krumsvik, R. J. (2014). Teacher Educators' Digital Competence. Scandinavian Journal of Educational Research, 58, 269-280. https://doi.org/10.1080/00313831.2012.726273

Madge, C., Meek, J., Wellens, J., \& Hooley, T. (2009). Facebook, Social Integration and Informal Learning at University: It Is More for Socialising and Talking to Friends about Work than for Actually Doing Work. Learning, Media and Technology, 34, 141-155. https://doi.org/10.1080/17439880902923606

Mazer, J. P., Murphy, R. E., \& Simonds, C. J. (2007). I'll See You on “Facebook": The Effects of Computer-Mediated Teacher Self-Disclosure on Student Motivation, Affective Learning, and Classroom Climate. Communication Education, 56, 1-17. https://doi.org/10.1080/03634520601009710

McLoughlin, C., \& Lee, M. J. (2008). Future Learning Landscapes: Transforming Pedagogy through Social Software. Innovate: Journal of Online Education, 4, Article 1.

Moran, M., Seaman, J., \& Tinti-Kane, H. (2011). Teaching, Learning, and Sharing: How Today's Higher Education Faculty Use Social Media. Babson Survey Research Group.

Pestek, A., Kadic-Maglajlic, S. E. L. M. A., \& Nožica, M. (2012). Implications of Web 2.0 Usage in Higher Education. International Journal of Management Cases, 14, 3-12. https://doi.org/10.5848/APBJ.2012.00002

Safori, A. O. (2018). Social Media's Impact on a Journalist's Role. Journal of Science Education, 19, 148-162.

Sheldon, P. (2015). Understanding Students' Reasons and Gender Differences in Adding Faculty as Facebook Friends. Computers in Human Behavior, 53, 58-62. https://doi.org/10.1016/j.chb.2015.06.043

Siemens, G. (2005). Connectivism: A Learning Theory for the Digital Age. International Journal of Instructional Technology and Distance Learning, 2, 3-10.

Statista (2016). Leading Social Networks Worldwide as of January 2016. http://www.statista.com/statistics/272014/global-social-networks-ranked-by-number-o $\underline{\text { f-users }}$ 
Taylor, L., McGrath-Champ, S., \& Clarkeburn, H. (2012). Supporting Student Self-Study: The Educational Design of Podcasts in a Collaborative Learning Context. Active Learning in Higher Education, 13, 77-90. https://doi.org/10.1177/1469787411429186

Tømte, C., Enochsson, A. B., Buskqvist, U., \& Kårstein, A. (2015). Educating Online Student Teachers to Master Professional Digital Competence: The TPACK-Framework Goes Online. Computers \& Education, 84, 26-35.

https://doi.org/10.1016/j.compedu.2015.01.005 